\section{Key Words}

dibromophakellstatin total synthesis tetracyclic imidazolinones alkaloids

\title{
Total Synthesis of the Marine Natural Product rac-Dibromophakellstatin
}

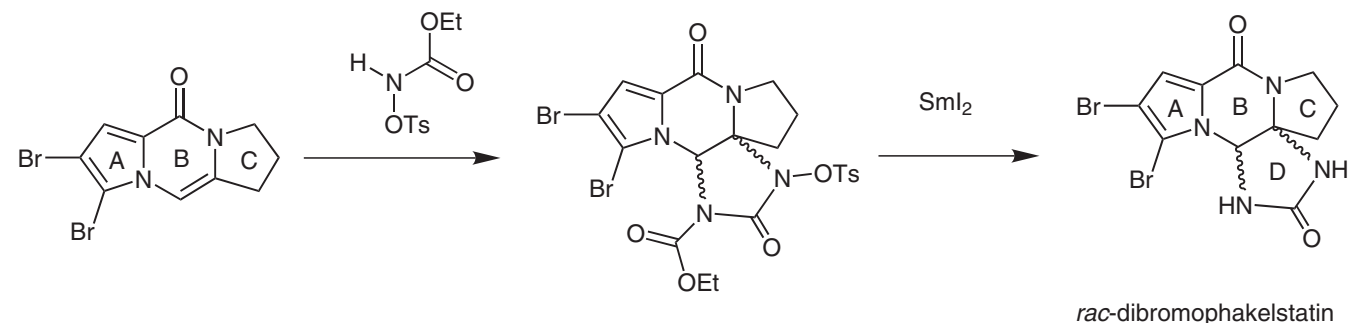

